\title{
In-Well Sediment Incubators to Evaluate Microbial Community Stability and Dynamics Following Bioimmobilization of Uranium
}

\author{
Brett Baldwin ${ }^{1}$, Aaron D. Peacock ${ }^{2}$, Ying-Dong (Margaret) Gan ${ }^{3}$, C. Tom Resch ${ }^{4}$, Evan \\ Arntzen $^{4}$, Amanda N. Smithgall ${ }^{3}$, Susan M. Pfiffner ${ }^{5}$, Barry M. Freifeld ${ }^{6}$, David C. \\ White $^{2}$, and Philip E. Long ${ }^{4}$ \\ ${ }^{1}$ Microbial Insights, Rockford, TN \\ ${ }^{2}$ Oak Ridge National Laboratory, Oak Ridge, TN \\ ${ }^{3}$ University of Tennessee Center for Biomarker Analysis, Knoxville, TN \\ ${ }^{4}$ Pacific Northwest National Laboratory, Richland, WA \\ ${ }^{5}$ University of Tennessee Center for Environmental Biotechnology, Knoxville, TN \\ ${ }^{6}$ Lawrence Berkeley National Laboratory, Berkeley California (BMF's work was partially supported by the \\ U.S. Department of Energy and LBNL under Contract No. DE-AC02-05CH11231.)
}

An in-well sediment incubator (ISI) was developed to investigate the stability and dynamics of sediment-associated microbial communities to prevailing subsurface oxidizing or reducing conditions. Herein we describe the use of these devices at the Old Rifle Uranium Mill Tailings Remedial Action (UMTRA) site. During a seven-month period in which oxidized Rifle Aquifer background sediment (RABS) were deployed in previously biostimulated wells under ironreducing conditions, cell densities of known iron-reducing bacteria, including Geobacteraceae, increased significantly, showing the microbial community response to local subsurface conditions. Phospholipid fatty acid (PLFA) profiles of RABS following in situ deployment were strikingly similar to those of adjacent sediment cores, suggesting ISI results could be extrapolated to the native material of the test plots. Results for ISI deployment with laboratory-reduced sediments showed only slight changes in community composition and pointed toward the ability of the ISI to monitor microbial community stability and response to subsurface conditions.

\section{INTRODUCTION}

Enhanced bioremediation, whether for petroleum hydrocarbons, chlorinated solvents, or radionuclides, frequently involves subsurface injection of an amendment (electron acceptor or donor) to stimulate microbial activity. Following injection, temporal groundwater monitoring programs are commonly instituted to track contaminant concentrations, geochemical parameters, and changes in microbial community composition. Although groundwater monitoring can provide valuable insight into biological processes, important microbial populations, and contaminant transformations may be strongly associated with the subsurface matrix (Bekins et al., 1999; Hazen et al., 1991; Thomas et al., 1998) as opposed to the planktonic communities. Collection of sediment cores allows interrogation of sediment-associated transformations. However, repeated drilling events are expensive and not always practical, especially in deeper aquifer systems. To combat this problem, a number of researchers have employed in situ microcosms in which native sediment or a sediment surrogate is deployed and recovered from existing monitoring wells (Bennett et al., 2000; Hendricks et al., 2005; Peacock et al., 2004; Reardon et al., 2004). The in situ microcosm approach, however, is 
The cornerstone of the in-well sediment incubator approach is that analysis of recovered microcosms provides interpretable results consistent with sediment core samples. potentially limited by the extent to which the results relate to the native sediment and the aquifer as a whole (Bennett et al., 2000). Therefore, the cornerstone of the in-well sediment incubator approach is that analysis of recovered microcosms provides interpretable results consistent with sediment core samples.

In aerobic aquifers typical of many Department of Energy (DOE) legacy waste sites, uranium is present in the oxidized $\mathrm{U}(\mathrm{VI})$ form, which is more soluble and, thus, more mobile (Anderson et al., 2003; Istok et al., 2004; Wall \& Krumholz, 2006). A wide variety of dissimilatory metal-reducing bacteria, most notably of the genera Geobacter and Shewanella, have been shown to enzymatically reduce U(VI) to less soluble U(IV) forms (Gorby \& Lovley, 1992; Lovley \& Phillips, 1992; Lovley et al., 1991; Wall \& Krumholz, 2006). Therefore, in situ immobilization of uranium by microbial reduction of soluble $\mathrm{U}(\mathrm{VI})$ has been suggested as a remediation strategy to limit migration of uraniumimpacted groundwater (Lovley \& Phillips, 1992; Lovley et al., 1991). Field experiments at the Old Rifle Uranium Mill Tailings Remedial Action (UMTRA) site have shown that electron-donor addition (acetate) stimulates iron-reducing bacteria (IRB), such as Geobacter, and promotes the reduction of U(VI) (Anderson et al., 2003; Holmes et al., 2002). However, examination of sediment core samples has revealed that, although soluble $\mathrm{U}(\mathrm{VI})$ was readily reduced, sediment-associated $\mathrm{U}(\mathrm{VI})$ was not microbially reduced (Ortiz-Bernad et al., 2004). Furthermore, oxidation of precipitated U(IV) can proceed if nitrate or sulfate reduction is occurring in the presence of $\mathrm{Fe}(\mathrm{III})$ minerals or abiotically in the presence of oxygen (Wall \& Krumholz, 2006). Despite the potential for oxidative dissolution, field experiments have demonstrated that rapid reoxidation does not occur at the Old Rifle site, and maintenance of bioreduced uranium is the subject of ongoing experiments (N'Guessan et al., 2008).

In this current study, in-well sediment incubators (ISIs) were deployed to serve as in situ microcosms for evaluating the postamendment-phase stability of microbial populations at the Old Rifle site. ISIs contained oxidized Rifle Aquifer background sediment (RABS) that had been reduced under iron-reducing conditions and RABS that had been reduced under sulfate-reducing conditions (herein referred to as IR and SR sediments, respectively). These ISIs were deployed in background and previously stimulated monitoring wells for approximately seven months (December 2006 through June 2007). Groundwater samples were collected monthly to determine geochemical conditions and dominant terminal electron-accepting processes during deployment. Phospholipid fatty acid (PLFA) and quantitative polymerase chain reaction (qPCR) analyses of time 0 sediments and recovered ISI sediments were used to evaluate changes in and the stability of microbial community composition during the postamendment phase (e.g., the persistence of IRB). Results for recovered ISIs were compared to those of adjacent sediment core samples to evaluate the utility of the ISI approach as a tool for assessing the stability of biostimulated microbial communities.

\section{MATERIALS AND METHODS}

\section{Field Site}

The Old Rifle UMTRA site (Rifle, Colorado) is a former uranium ore processing facility where spent mill tailings leachate resulted in sediment and groundwater contamination. 


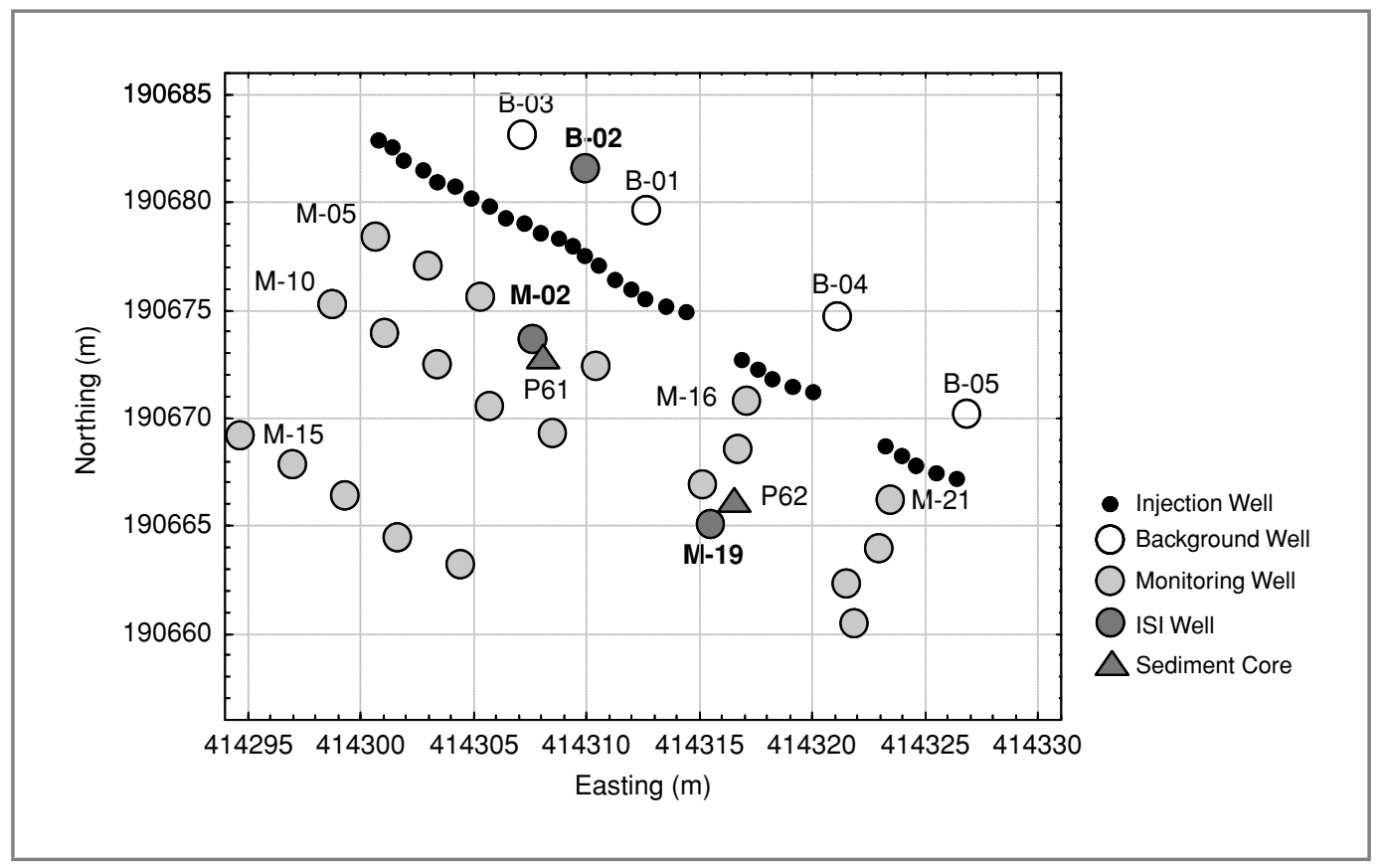

Exhibit 1. Rifle well plot with ISI locations highlighted

Under the DOE Environmental Remediation Sciences Program (ERSP), the site has been designated an Integrated Field Research Challenge (IFRC) site and utilized for extensive field studies of bioimmobilization of uranium. The aquifer is an alluvial deposit composed of unconsolidated clay, sand, silt, gravel, and cobbles to a depth of approximately $6.9 \mathrm{~m}$ below land surface. Detailed descriptions of the site geology, test plots, and acetate injection experiments are available elsewhere (Anderson et al., 2003; Holmes et al., 2002; Vrionis et al., 2005) but will be summarized for the ISI deployments (Exhibit 1). ISIs were deployed in wells B-02 and M-02 in the original test plot described by Anderson et al. (2003). B-02 is a background monitoring well located $5 \mathrm{~m}$ upgradient of the original test plot acetate injection gallery. M-02 is approximately $5 \mathrm{~m}$ downgradient of the original injection gallery, which was used in the 2004 and 2005 experiments. ISIs were also deployed in M-19 approximately $7 \mathrm{~m}$ downgradient of the injection gallery used for 2006 experiments (two months prior to ISI deployment).

\section{In-Well Sediment Incubator Design}

ISIs were constructed from 0.6-m sections of 3-inch Schedule 40 PVC pipe (Exhibit 2). Slots were removed from the ISI body to accommodate the porous $(90-130 \mu \mathrm{m})$ polyethylene liner (Porex ${ }^{\mathrm{TM}}$, Sutton, Massachusetts), which retained loaded sediment while permitting groundwater flow through the ISI when deployed. PVC end caps that seal the ISI body were constructed with tubing pass-throughs for groundwater monitoring. For the prototype ISI, packers inflated with nitrogen gas were used to isolate the ISI vertically within the well. In subsequent deployments, end caps equipped with o-rings were used for vertical isolation. ISI were attached to PVC risers to be deployed approximately $4.9 \mathrm{~m}$ below the top of the well casing. 


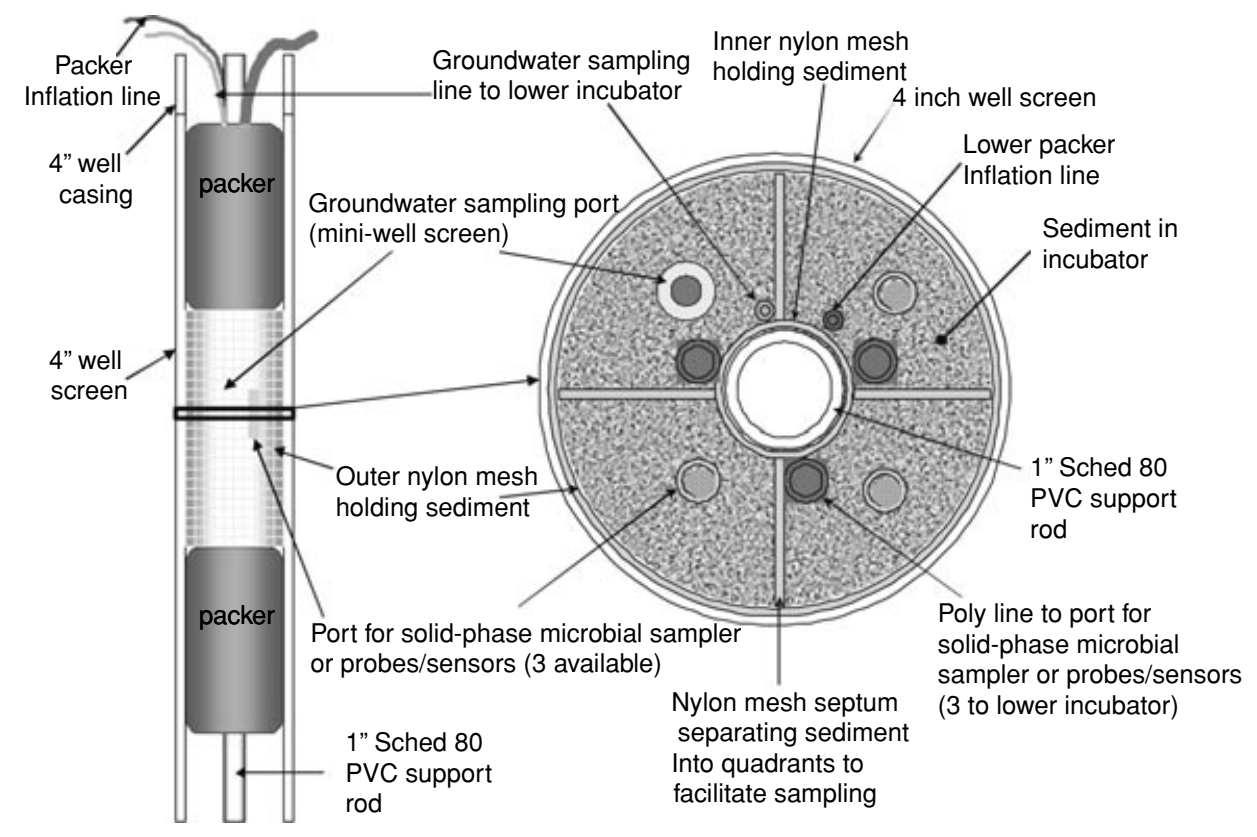

Exhibit 2. In-well sediment incubator design features

\section{GENERATION OF REDUCED RIFLE AQUIFER SEDIMENT}

To investigate the microbial community response under field conditions, ISI containing either native oxidized RABS, laboratory iron-reduced RABS (IR), or laboratory sulfate-reduced RABS (SR) were generated. For reduced sediments, laboratory microcosms containing approximately $500 \mathrm{~g}$ of RABS were amended with $400 \mathrm{~mL}$ of iron-reducing medium $\left(2.5 \mathrm{~g} / \mathrm{L}\right.$ of $\mathrm{NaHCO}_{3}, 0.1 \mathrm{~g} / \mathrm{L}$ of $\mathrm{KCl}, 1.5 \mathrm{~g} / \mathrm{L}$ of $\mathrm{NH}_{4} \mathrm{Cl}$, $10 \mathrm{~mL} / \mathrm{L}$ of trace mineral solution, $1.0 \mathrm{~mL} / \mathrm{L}$ of $10 \mathrm{X}$ vitamin solution, $0.1 \mathrm{~g} / \mathrm{L}$ of MOPS, $20 \mathrm{mM}$ of $\mathrm{CH}_{3} \mathrm{COONa}$, and $1.0 \mathrm{~mL} / \mathrm{L}$ of 0.1 percent resazurin solution) or sulfate-reducing medium $\left(0.9 \mathrm{~g} / \mathrm{L}\right.$ of $\mathrm{NaCl}_{2}, 0.2 \mathrm{~g} / \mathrm{L}$ of $\mathrm{MgCl}_{2}-6 \mathrm{H}_{2} \mathrm{O}, 1.0 \mathrm{~g} / \mathrm{L}$ of $\mathrm{NH}_{4} \mathrm{Cl}_{2}, 10 \mathrm{~mL} / \mathrm{L}$ of trace mineral solution, $1.0 \mathrm{ml} / \mathrm{L}$ of $10 \mathrm{X}$ vitamin solution, $0.1 \mathrm{~g} / \mathrm{L}$ of MOPS, $10 \mathrm{mM}$ of $\mathrm{NaSO}_{4}, 40 \mathrm{mM}$ of $\mathrm{CH}_{3} \mathrm{COONa}$, and $1.0 \mathrm{ml} / \mathrm{L}$ of 0.1 percent resazurin solution; Phelps et al., 1989). The redox state was adjusted by addition of 2 percent Cysteine- $\mathrm{HCl}$ as needed. The microcosms were shaken every three or four days to mix the sediment and were incubated upside down at room temperature for 14 days. To maintain anoxic sediment conditions, the IR and SR sediments were loaded into the ISI apparatus inside a Coy anaerobic chamber. The loaded ISIs were inserted into space bags under nitrogen gas to reduce the possibility of oxygen contamination during shipment and shipped to the Rifle site on blue ice in order to reduce microbial community changes during transit. Incubators containing RABS were loaded on-site as dry sediments in air. Subsamples of RABS, IR, and SR were retained prior to deployment (time 0) for PLFA analysis, qPCR enumeration of microbial community members, and denaturing gradient gel electrophoresis (DGGE) separation and sequence analysis. 


\section{ISI DEPLOYMENTS AT THE OLD RIFLE SITE}

In December 2006, a total of six ISIs were deployed at the Old Rifle UMTRA site. In addition to the sediments, each ISI also contained a Bio-Trap ${ }^{\circledR}$ loaded with Bio-Sep ${ }^{\circledR}$ beads. ISIs containing IR and SR sediments were deployed in background monitoring well B-02, upgradient of the original test plot. ISIs containing SR and RABS sediments were installed in previously stimulated monitoring well M-02 (acetate injections in 2004 and 2005) located in the original test plot. ISIs containing IR and RABS sediments were deployed in monitoring well M-19, which had been driven to iron-reducing conditions during the 2006 acetate-injection experiment, which concluded approximately two months prior to ISI deployment. All incubators were deployed to a depth of approximately $4.9 \mathrm{~m}$ below the top of the casing. ISIs were installed on December 1, 2006, and recovered during the June 17, 2007, drilling event.

\section{SEDIMENT CORE DRILLING}

Sediment core samples adjacent to deployment wells (M-02 and M-19) were obtained for comparison to ISI sediments. Coring was performed using a Rotosonic drilling rig (Boart Longyear, Environmental and Infrastructures Services, Peoria, Arizona) to a depth of $6.1 \mathrm{~m}$ below land surface (bls). Drilling procedures and protocols for high-quality sediment samples have been previously described (Phelps \& Fredrickson, 2002). Core samples were sectioned and logged by depth. Samples from depths of approximately 4.6 to $5.2 \mathrm{~m}$ bls were transferred to $\mathrm{N}_{2}$-filled portable glove bags and subsampled. Efforts were made to remove larger cobbles $(>3 \mathrm{~cm})$ from samples. Samples for molecular analysis were immediately placed on dry ice. Samples were shipped to the laboratory by overnight courier and stored at $-80^{\circ} \mathrm{C}$ (molecular) prior to analysis.

\section{PHOSPHOLIPID (PLFA) ANALYSIS}

Sediment samples were extracted with a single-phase chloroform-methanol buffer system (White et al., 1979). The total lipid portion was then fractionated, using a silicic acid column, into three lipid categories: neutral lipids, glycolipids, and polar lipids (Guckert et al., 1985). After fractionation, the polar lipid portion was transesterified to form fatty acid methyl esters (FAMEs) by mild alkaline methanolysis (Guckert et al., 1985), as modified by Mayberry and Lane (1993) to release plasmalogen ethers as dimethylacetals (DMAs). The FAMEs and DMAs were analyzed by gas chromatography/mass spectroscopy using an Agilent 6890 series gas chromatograph interfaced with an Agilent 5973 mass spectrometer (Santa Clara, California).

\section{ANALYSIS OF GROUNDWATER SAMPLES}

Groundwater samples were collected from background wells B-03, B-04, and B-05 (adjacent to B-02); previously stimulated monitoring wells M-16 and M-17 (near M-19); and M-08 on a monthly basis during the deployment. Groundwater parameters $(\mathrm{pH}$, dissolved oxygen, conductivity, and redox potential) were determined by using a peristaltic pump, flow cell, and multiprobe datasonde (Hydrolab-Hach Company,
Sediment samples were extracted with a single-phase chloroform-methanol buffer system. The total lipid portion was then fractionated, using a silicic acid column, into three lipid categories: neutral lipids, glycolipids, and polar lipids. 
Chicago, Illinois), as detailed previously (Anderson et al., 2003). All wells were purged (ca. $12 \mathrm{~L}$ ) prior to sample collection. Samples were obtained for U(VI), anion (bromide, nitrate, and sulfate), Fe(II), acetate, and sulfide analyses as previously described (Anderson et al., 2003).

\section{DNA EXTRACTION AND QPCR}

Several molecular studies have indicated members of the Geobacteraceae family may be the dominant microorganisms in sediment environments under ironreducing conditions.
DNA was extracted from recovered ISI sediments and sediment cores using the Power Soil DNA extraction kit (MO BIO Laboratories, Carlsbad, California) per the manufacturer's protocol. Bacteria were enumerated by qPCR using PCR primers BACT1369F-PROK1492R with the TaqMan probe1389F as described previously (Suzuki et al., 2000). The PCR primer set 361F-685R specific for the $16 \mathrm{~S}$ rRNA gene of $\delta$-Proteobacteria (Stults et al., 2001) and the TaqMan probe $1839 \mathrm{~F}$ were used as an index of potential sulfate-reducing and iron-reducing bacteria. Several molecular studies have indicated members of the Geobacteraceae family may be the dominant microorganisms in sediment environments under iron-reducing conditions (Anderson et al., 1998; Holmes et al., 2002; Roling et al., 2001; Snoeyenbos-West et al., 2000). PCR primer set 561F-825R and TaqMan probe Gbc2 specific for Geobacter sp. (Stults et al., 2001) were used to enumerate potential iron-reducing bacteria. The 60F-461R primer pair was used to enumerate Anaeromyxobacter spp. (Petrie et al., 2003). All real-time PCR was performed on an ABI Prism 7000 Sequence Detector or an ABI 7300 Real-Time PCR System (Applied Biosystems, Foster City, California). All experiments included control reaction mixtures without added DNA and calibration curves with appropriate positive control DNA.

\section{DGGE AND SEQUENCE ANALYSIS}

DGGE was performed using the D-Code ${ }^{\mathrm{TM}} 16 / 16 \mathrm{~cm}$ gel system (BioRad, Hercules, California) as described previously (Chang et al., 2000). Gels were imaged using Labworks software (UVP, Upland, California). Intense bands were excised and purified using an UltraClean PCR Clean-Up DNA Purification kit (MO BIO Laboratories, Inc., Carlsbad, California). Following purification and quantification, the excised bands were subjected to sequence analysis. Sequences were aligned with ClustalW (http://clustalw.genome.jp/) and refined manually. Comparative identifications and phylogenetic analysis was performed with Accelrys Gene (version 2.5, Accelrys, San Diego, California).

\section{RESULTS}

\section{Geochemical Conditions During ISI Deployment}

During the ISI deployment, groundwater samples were obtained from adjacent monitoring wells to evaluate predominant geochemical conditions in background (B-02), recently stimulated (M-19), and previously stimulated (M-02) areas. Under background conditions, the average redox potential during the final deployment was $165.6 \mathrm{mV}$, the average dissolved oxygen concentration (DO) was $0.42 \mathrm{mg} \mathrm{L}^{-1}$, and the area could be described as mildly aerobic (Exhibit 3). Conversely, redox potentials in the vicinity of 


\section{Parameter Mean (SD)}

Eh $(\mathrm{mV})$

Dissolved Oxygen $(\mathrm{mg} / \mathrm{L})$

Unfiltered $\mathrm{Fe}^{2+}(\mathrm{mM})$

Filtered $\mathrm{Fe}^{2+}(\mathrm{mM})$

Sulfate (mM)

Unfiltered Sulfide (mM)

Uranium (mM)
Background (B-02) ${ }^{1}$ Original Plot (M-02) 2004 Gallery (M-19) 3
$165.6 \pm 55$
$0.42 \pm 0.3$
$11.3 \pm 7$
$0.32 \pm 0.3$
$10.36 \pm 1.3$
$0.9 \pm 1.6$
$1.22 \pm 0.4$

$85.5 \pm 16$

$0.29 \pm 0.1$

$100 \pm 30$

$3.31 \pm 0.1$

$11.93 \pm 1.3$

$1.28 \pm 0.5$

$0.97 \pm 0.5$ $\mathbf{8 1 . 5} \pm \mathbf{3 6}$

$0.54 \pm 0.5$

$41.2 \pm 22$

$1.54 \pm 0.8$

$10.19 \pm 1.7$

$2.18 \pm 4.4$

$1.13 \pm 0.4$

Mean values \pm standard deviation for monthly monitoring events (11/06 through 6/07).

Bold indicates significantly different from background $(\alpha=0.05)$.

${ }^{1}$ Includes background wells B-03, B-04, and B-05.

${ }^{2}$ Includes $\mathrm{M}-08$ in the original test plot.

${ }^{3}$ Includes M-16 and M-17 of the 2006 test plot.

M-02 $(85.5 \mathrm{mV})$ and M-19 $(81.5 \mathrm{mV})$ were significantly lower than under background conditions $(\alpha=0.05)$. Likewise, ferrous iron concentrations in the M-02 and M-19 areas were significantly greater than background, as was expected for previously stimulated wells. Based on sulfate and sulfide concentrations, dissimilatory sulfate reduction was not significant in background or previously stimulated areas.

\section{Hierarchical Cluster Analysis of PLFA Profiles}

An exploratoryhierarchical cluster analysis (Ward's Method) based on PLFA profiles revealed two primaryclusters (Exhibit 4) composed in general of Background/RABS (A) and reduced sediments (B). The background and RABS-associated primary cluster (A) contained significantly greatermidchain-branched, terminally branched, and branched monounsaturated fatty acids, whereas primary cluster B had significantly greater monounsaturates suggesting enrichment of Gram-negative bacteria (Proteobacteria) in the reduced sediments. Within primary cluster $\mathrm{A}$, the background sediment core samples U-01 and U-03 formed a secondary cluster (A-1) distinct from the A-2 secondary cluster, which contained RABS, ISI-deployed RABS, and adjacent sediment core samples. Tertiary (A-2-2) and quaternary structure subclusters were also noted. ISI-incubated RABS deployed in M-02 and M-19 were more similar to their corresponding sediment core samples than to each other and the RABS (time 0) subcluster, suggesting that the ISI microbial community composition responded to local (reducing) subsurface conditions. Primary cluster B also showed a distinct secondary structure, where ISI-deployed reduced sediments (B-1) and time 0 reduced sediments (B-2) formed unique clades, indicating shifts in microbial community composition during ISI deployment. Within the secondary B-1 cluster, reduced sediment and Bio-Traps ${ }^{\circledR}$ deployed in background well B-02, iron-reducing sediment deployed in previously stimulated well M-19, and sulfate-reducing sediment incubated in M-02 all formed distinct subclusters likely due to different geochemical conditions at each well. 


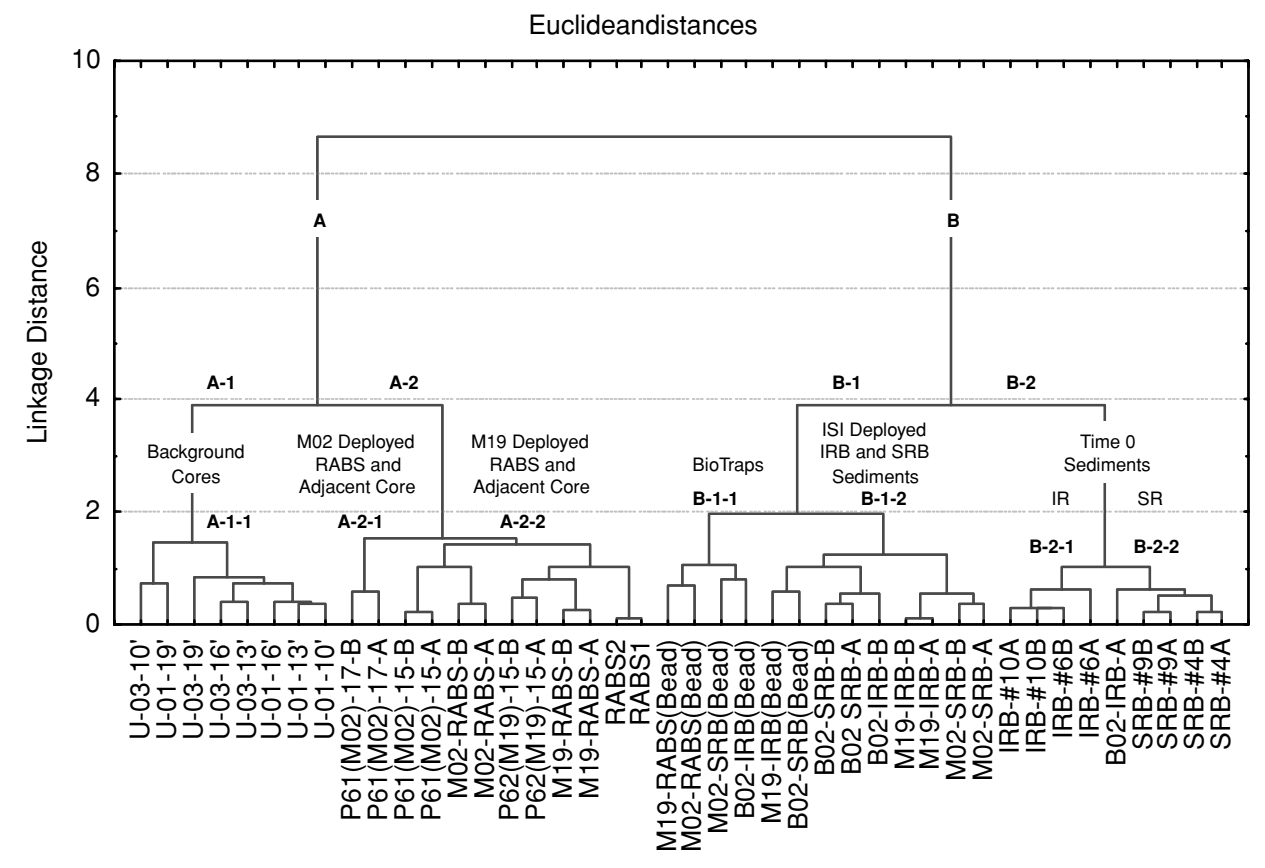

Exhibit 4. Hierarchical cluster analysis of microbial PLFA profiles from ISI and native site sediment

\section{CHANGES IN MICROBIAL COMMUNITY COMPOSITION DURING ISI DEPLOYMENT}

The hierarchical cluster analysis of PLFA profiles discussed previously clearly indicated changes in the sediment microbial community composition during ISI deployments and suggests that observed shifts in sediment microbial populations were related to both the redox state of the time 0 sediment and subsurface conditions (Deployment Well). Subsamples of RABS under iron-reducing (IR) conditions and Rifle sediment under sulfate-reducing (SR) conditions were obtained for baseline PLFA profiles, enumeration of specific bacterial groups, and DGGE profiles with sequence analysis prior to ISI deployment (Exhibit 5). In RABS, monounsaturates ( $\sim 34$ percent) were the dominant PLFA with saturates $(\sim 24$ percent $)$, midchain-branched ( $\sim 17$ percent), and terminally branched ( $\sim 18$ percent) PLFAs as significant fractions. The $\delta$-Proteobacteria population $\left(10^{3}\right.$ cells/g), used as an index of iron- and sulfate-reducing bacteria, and Geobacteraceae population $\left(10^{2}\right.$ cells $\left./ \mathrm{g}\right)$ were relatively low, as anticipated for oxidized sediments (Exhibit 5). The median sulfate reducer population as indicated by quantification of dissimilatory sulfite reductase (DSR) gene copies was on the order of $10^{4}$ cells $/ \mathrm{g}$, but replicates ranged from below the quantitation limit to as high as $10^{7} \mathrm{cells} / \mathrm{g}$. Based on sequences of dominant bands in the DGGE profiles, Chloroflexi (green nonsulfur bacteria), Actinobacteria, and Acidobacteria appeared to be the dominant members of the microbial community in background sediments. In previous clone library results, $\beta$-Proteobacteria, and Actinobacteria were the most prevalent, followed by Acidobacteria and other minor constituents (Vrionis et al., 2005). 


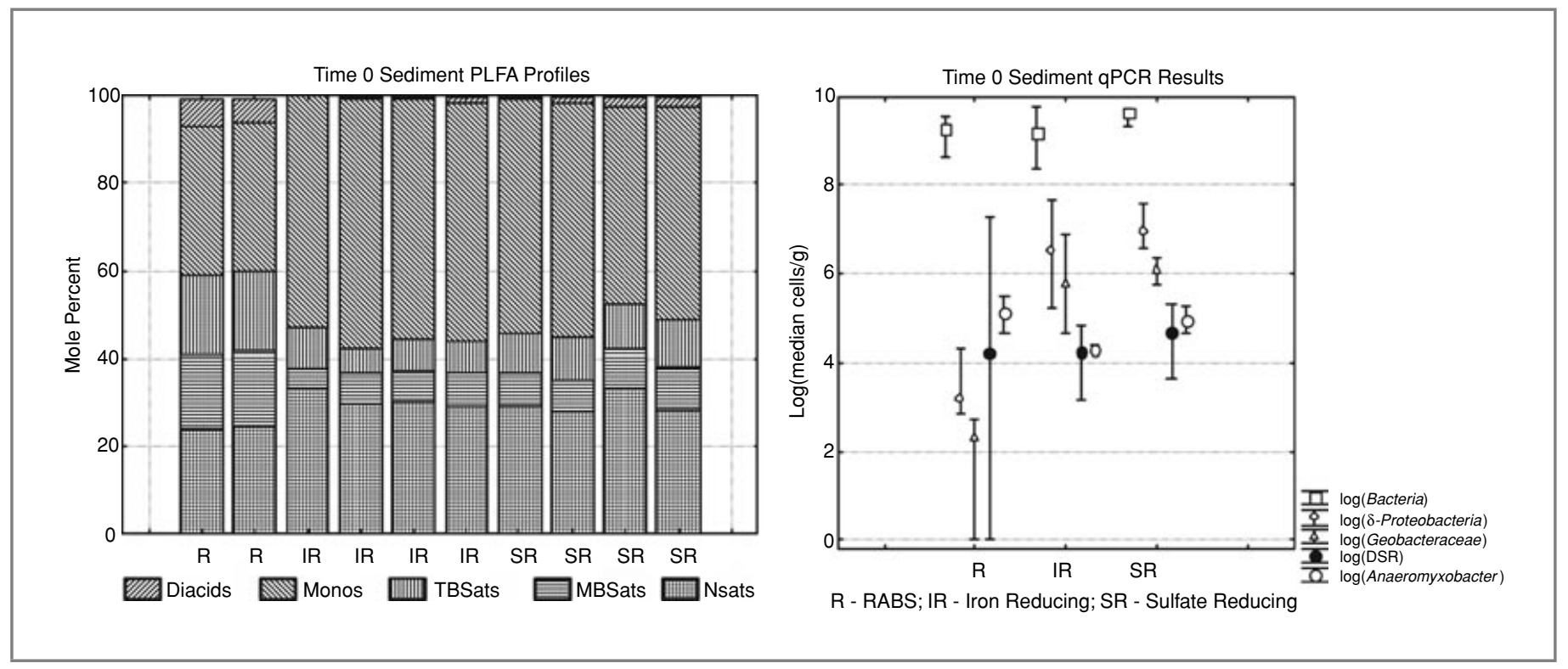

Exhibit 5. Microbial community composition of time 0 sediments

When driven to iron-reducing conditions and sulfate-reducing conditions in the laboratory, $\delta$-Proteobacteria and Geobacteraceae cell densities increased significantly $(\alpha=0.05)$. Likewise, the mole fraction of monounsaturates, an indicator of Gram-negative bacteria (Proteobacteria), increased significantly and 16S rRNA gene sequences corresponding to $\delta$-Proteobacteria were recovered from denaturing gradient gel electrophoresis (DGGE) profiles of iron-reducing sediment. Despite being driven to sulfate-reducing conditions, no significant increases in dissimilatory sulfite reductase (DSR) gene copies were noted.

\section{ISI-Deployed RABS}

An ISI containing RABS was deployed in M-02 located in the original test plot, which last received acetate in 2005. As mentioned previously, the redox potential of the original test plot during the ISI deployment was significantly lower than in background wells

(Exhibit 3). Fe(II) production and the lack of sulfate consumption suggested predominantly iron-reducing conditions. During RABS in-well incubation in M-02, the $\delta$-Proteobacterial population increased significantly ( $\log 3$ to $\log 5$; Exhibit 6). Likewise, Geobacteraceae increased by an order of magnitude, indicating enrichment of iron-reducing bacteria in the ISI-deployed RABS. DSR gene copies decreased to below quantitation limits, which was consistent with the observed decrease in midchain-branched saturates and environmental conditions.

An ISI containing RABS was also deployed in downgradient well M-19 located in the 2005 gallery, which last received acetate three months prior to ISI installation. As with M-02, the redox potential of M-19 was significantly lower than background, and Fe(II) and sulfate concentrations indicated iron-reducing conditions during deployment (Exhibit 3). During the incubation of RABS in M-19, $\delta$-Proteobacteria and Geobacteraceae populations 


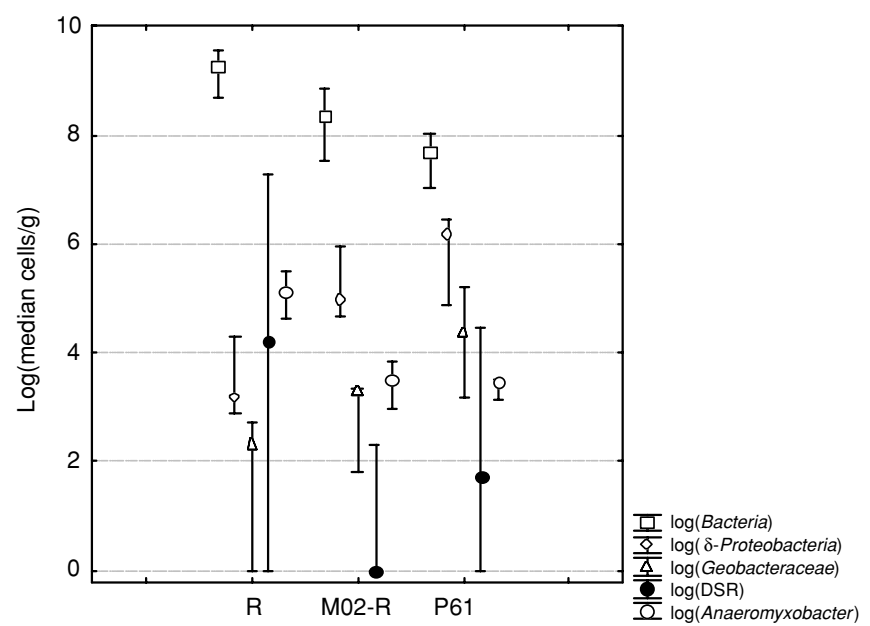

R - RABS; M02-R - ISI Deployed RABS; P61 - Adjacent Core

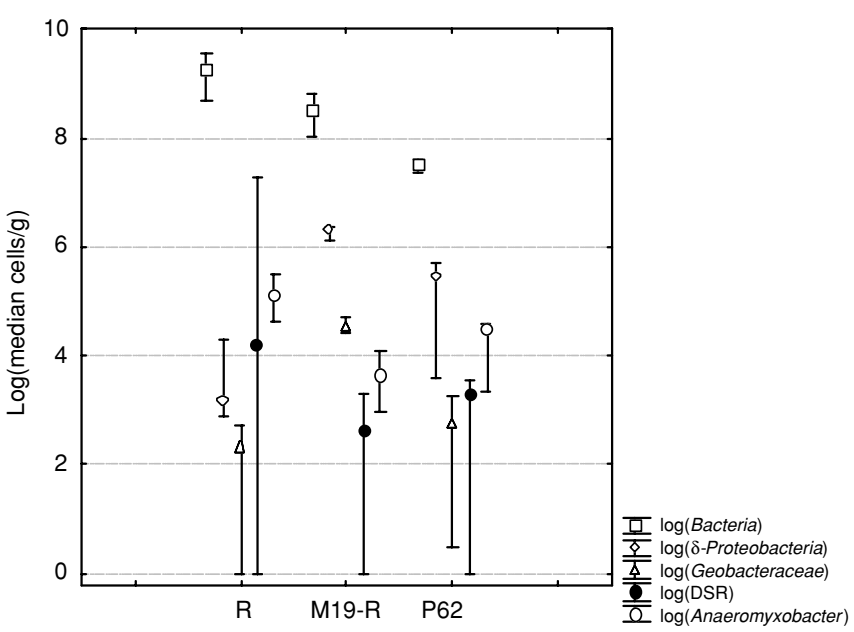

R - RABS; M19-R - ISI Deployed RABS; P62 - Adjacent Core

Exhibit 6. ISI-deployed RABS and sediment cores

increased significantly while DSR copies decreased, which corresponds to increases in monounsaturates and decreases in midchain-branched saturates, respectively (Exhibit 6).

To determine whether the results for the ISI-deployed RABS could be extrapolated to the native aquifer sediments, qPCR results were compared to those of adjacent sediment core samples obtained at the end of the deployment. As noted previously, the PLFA profiles of M-02-R were most similar to those of the adjacent P-61 sediment core at a depth of 15 feet. The abundances of $\delta$-Proteobacteria and Geobacteraceae were slightly lower in the M-02-IR than in P-61; however, no significant differences $(\alpha=0.05)$ were noted between the microbial community composition of the P-61 sediment core and recovered ISI sediments. Furthermore, the increase in $\delta$-Proteobacteria and Geobacteraceae follows the observed trend between the RABS and the native sediment. As with M-02, the PLFA profiles of M-19-R were most closely related to those of the adjacent sediment core P-62. Again, the abundance of potential iron-reducing bacteria in M-19-R did not precisely match those of the P-62 core, but Proteobacteria and Geobacteraceae cell densities were greater than in the RABS, showing the response of the microbial community to environmental conditions. Overall, results for the ISI-deployed RABS indicated enrichment of iron-reducing bacteria consistent with subsurface conditions and suggested that ISI-deployed sediments would respond to local geochemical conditions and could serve as a surrogate for sediment core samples.

\section{ISI-Deployed Iron-Reducing Sediments}

An ISI containing Rifle sediment driven to iron-reducing conditions was deployed in background well B-02 located upgradient of the original test plot to determine whether the ISI could be used to examine the impact of the influx of oxidized background groundwater on the stability of bioreduced uranium. Dissolved oxygen in the background wells during the ISI deployment was relatively low $(\sim 0.42 \mathrm{mg} / \mathrm{L})$, but the redox 


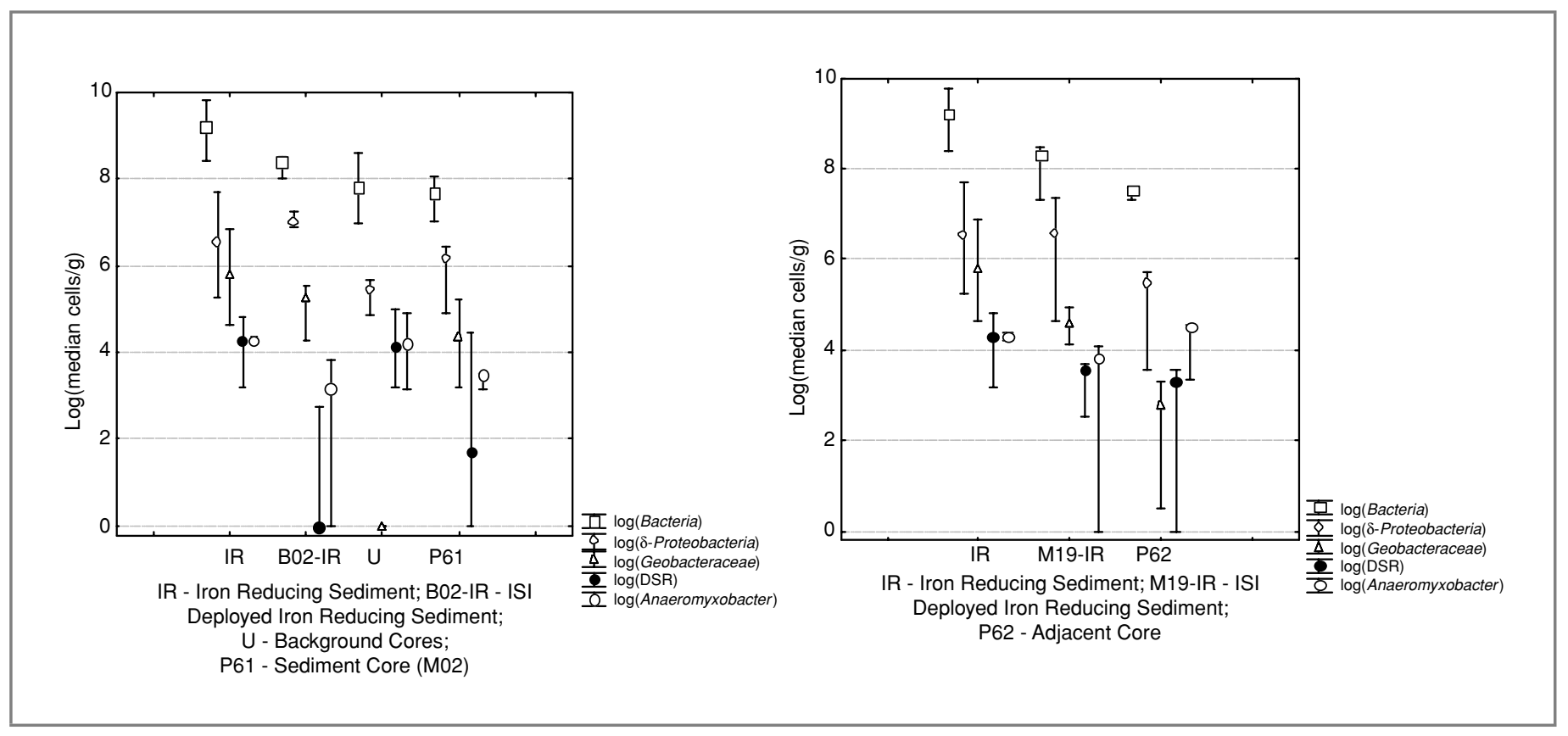

Exhibit 7. ISI deployed laboratory-reduced sediments and sediment cores

potential was significantly greater than in downgradient wells (Exhibit 3). Furthermore, $\mathrm{Fe}(\mathrm{II})$ concentrations were lower than in previously stimulated wells suggesting mildly aerobic background conditions. Despite oxidizing conditions, no significant changes were evident in the PLFA profile (data not shown) and median $\delta$-Proteobacteria and Geobacteraceae populations in B-02-IR remained on the order of $10^{6}$ and $10^{4}$ cells $/ g$, respectively, during ISI deployment. DSR gene copies decreased from $10^{4}$ cells $/ g$ to below quantitation limits. Again, ISI sediment results were compared to sediment cores to evaluate the feasibility of ISI as surrogates for sediment cores. The $\delta$-Proteobacteria and Geobacteraceae cell densities following deployment in B-02 were significantly greater than in background sediment core samples U-01 and U-03. Although seemingly counterintuitive, the time frame of ISI deployment must be considered during interpretation. ISIs containing biostimulated sediments were deployed in B-02 for approximately seven months, whereas the background U sediments have never been biostimulated. Instead, the B-02-IR results should be compared to those of the previously stimulated sediment cores. In P-61 sediment cores, $\delta$-Proteobacteria and Geobacteraceae abundances ranged from $10^{4}$ to $10^{6}$ cells $/ g$ two years after acetate injection had stopped, which is comparable to the $10^{5}$ to $10^{6}$ cells $/ g$ detected in B-02-IR (Exhibit 7). DSR copies in the B-02-deployed iron-reducing sediment were significantly lower than in the P-61 sediment core. However, the IR sediment deployed in the B-02 ISI had not been driven to sulfate-reducing conditions, whereas the original test plot had been subject to repeated acetate injections and sulfate reduction. Overall, the B-02 ISI results appear consistent with site observations that rapid changes in the sediment (attached) microbial community composition do not occur at the site following cessation of electron-donor addition.

An ISI containingIR sediment was also deployed in recently stimulated well M-19. Following in-well incubation, $\delta$-Proteobacterial cell densities remained at approximately $10^{6}$ cells $/ g$, although Geobacteraceae decreased by approximately an order of magnitude to 
The lack of significant shifts in the sediment microbial community is consistent with environmental conditions and the type of deployed sediment. $\sim 10^{4}$ cells $/ g$. Likewise, DSR copies decreased by an order of magnitude but remained above quantitation limits. Median $\delta$-Proteobacteria and Geobacteraceae cell densities in M-19 after deployment were approximately an order of magnitude greater than in the adjacent P-62 sediment core samples, although the differences were not statistically significant. Sulfate-reducing bacteria in both the M-19 ISI deployed with the IR sediment and the sediment core were on the order of $10^{3}$ cells $/ g$. The lack of significant shifts in the sediment microbial community is consistent with environmental conditions and the type of deployed sediment. Specifically, Rifle sediment driven to iron-reducing conditions was incubated in recently stimulated well M-19 under predominantly iron-reducing conditions.

\section{ISI-Deployed Sulfate-Reducing Sediments}

An ISI containing Rifle sediment under sulfate-reducing conditions was deployed in background well B-02. Following in-well incubation in B-02, significant changes in the PLFA profile and qPCR results were evident. Most notably, the fraction of midchain-branched saturates and branched monounsaturates decreased significantly ( $\alpha=$ $0.05)$, suggesting a decrease in sulfate reducers and anaerobic bacteria, respectively. Based on qPCR results, $\delta$-Proteobacteria and Geobacteraceae decreased in the ISI-deployed B-02-SR but were still on the order of $10^{6}$ and $10^{4}$ cells $/ g$, respectively. The population of sulfate-reducing bacteria, as indicated by enumeration of DSR gene copies, decreased from $10^{4}$ cells $/ g$ to below quantitation limits. As with the IR sediments, the microbial community composition of the B-02 deployed with sulfate-reducing sediments was significantly different than that of the background core samples (U-01 and U-03), as would be anticipated. When B-02-SR results were compared to those of the previously stimulated core P-61, only minor differences in microbial community composition were noted. $\delta$-Proteobacteria and Geobacteraceae were approximately $10^{6}$ and $10^{4} \mathrm{cells} / \mathrm{g}$ in the B-02-SR and P-61 samples. Although not statistically significant, DSR copies in P-61 samples were slightly greater than in B-02-SR, which was reflected in a greater fraction of midchain-branched saturates in the P-61 PLFA profile (data not shown). As with the iron-reducing sediments deployed in B-02, the results for the sulfate-reducing sediments deployed in B-02 indicated that rapid changes in the sediment microbial community composition did not occur, which is consistent with the site observation that up to 85 percent of influent $\mathrm{U}(\mathrm{VI})$ is removed even a year after the cessation of electron-donor addition (N'Guessan et al., 2008).

Sulfate-reducing sediments were also deployed in downgradient well M-02 located in the original test plot, which last received acetate in 2005. The redox potential of the original test plot during the ISI deployment was significantly lower than in background wells (Exhibit 3). Fe(II) production and the lack of sulfate consumption suggested predominantly iron-reducing conditions. Following M-02 deployment, the abundance of $\delta$-Proteobacteria decreased slightly but not significantly. Geobacteraceae also decreased but were still present on the order of $10^{4}$ cells $/ g$. DSR gene copies decreased from approximately $10^{4}$ cells $/ g$ to below quantitation limits, which corresponded to a decrease in the midchain-branched saturate fraction of the PLFA profile. When compared to the adjacent sediment core sample, P-61, no significant differences in $\mathrm{qPCR}$ results were noted. The $\delta$-Proteobacteria populations in both the recovered ISI and P-61 sediment cores 
were approximately $10^{6}$ cells $/ g$. Similarly, Geobacteraceae were slightly lower in the sediment core but were within an order of magnitude of the cell density detected in M-02-SR. Sulfate reducers were detected in P-61 but were near quantitation limits.

\section{DISCUSSION}

Field-scale acetate injections at the Old Rifle site have repeatedly demonstrated that electron-donor addition stimulates growth of iron-reducing bacteria, most notably Geobacteraceae, promoting bioreduction of dissolved U(VI). After depletion of bioavailable $\mathrm{Fe}(\mathrm{III})$ and the onset of sulfate-reducing conditions, loss of $\mathrm{U}(\mathrm{VI})$ from solution is significantly lower than under iron-reducing conditions. However, U(VI) removal in the post-biostimulation phase continues longer than expected, considering the known susceptibility of $\mathrm{U}(\mathrm{IV})$ to reoxidation. In fact, up to 85 percent of influent $\mathrm{U}(\mathrm{VI})$ is removed even a year after the cessation of electron-donor addition (N'Guessan et al., 2008). While the processes governing $\mathrm{U}(\mathrm{VI})$ reduction during the biostimulation phase are reasonably well characterized, the key factors controlling maintenance of bioreduced uranium remain poorly understood. The continued $\mathrm{U}(\mathrm{VI})$ removal may be the result of complex interactions involving sorption of $\mathrm{U}(\mathrm{VI})$ to Fe(III) oxides during shifts to more oxidizing conditions, sorption of U(VI) to microbial cells (N'Guessan et al., 2008), the $\mathrm{O}_{2}$ buffering capacity of iron sulfides formed during the sulfate-reduction phase, or U(VI) sorption to Fe-containing octahedral-layer edge sites. Recent evidence from experiments conducted at Rifle during 2007 (Mouser et al., in press) and 2008 suggest that ongoing Fe and $\mathrm{U}$ reduction associated with residual acetate may also be important (Long et al., 2008). Regardless of the mechanism, however, the common denominator with these hypotheses is that important microbial and abiotic interactions may be associated with the subsurface sediment and their attached biostimulated microbial populations, including Geobacteraceae (Wilkins et al., 2008).

Collection of sediment core samples provides the most direct avenue to explore biotic and abiotic interactions associated with the sediment, but repeated drilling is expensive and not always practical, especially to assess temporal changes. Bio-Trap ${ }^{\circledR}$ samplers containing Bio-Sep ${ }^{\mathrm{TM}}$ beads have been utilized at the site (Anderson et al., 2003), but the analysis of any surrogate solid phase is likely to have its own inherent set of biases (Peacock et al., 2004). Furthermore, the use of sediment surrogates does not allow for interrogation of the effect of minerals present in the native material. The ISIs were developed as a compromise between repeated drilling for sediment cores and the use of sediment surrogates permitting field deployment of amended and native sediments in a readily recovered/sampled platform. The basis of the ISI approach is that analysis of ISI-deployed sediments will provide interpretable results consistent with sediment core samples, which are more difficult and expensive to obtain.

The ISI method offers a unique approach to investigate microbial community dynamics in a field expedient platform but could potentially be limited by the extent to which observations can be extrapolated to the broader aquifer system. Overall, the results of the ISI deployments at the Old Rifle site show that ISIs can serve as surrogates or supplements to sediment core drilling. When oxidized RABS was deployed in previously stimulated wells under iron-reducing conditions, cell densities of known iron-reducing bacteria, including Geobacteraceae, increased significantly, reflecting the microbial
Field-scale acetate injections at the Old Rifle site have repeatedly demonstrated that electron-donor addition stimulates growth of iron-reducing bacteria, most notably Geobacteraceae, promoting bioreduction of dissolved $\mathrm{U}(\mathrm{VI})$. 
community response to local subsurface conditions. Moreover, the PLFA profiles of RABS following in situ deployment were strikingly similar to those of adjacent sediment cores (Hierarchical Cluster Analysis; Exhibit 4), strongly suggesting ISI results could be extrapolated to the native material of the test plots.

Results for ISI-deployed reduced sediments are less readily interpreted but nonetheless point toward the ability of the ISI to monitor microbial community response to subsurface conditions. First, PLFA profiles of reduced sediments following ISI deployment were significantly different from the time 0 starting materials, demonstrating a shift in the sediment microbial community. Second, hierarchical cluster analysis of PLFA profiles revealed subclusters based on deployment wells, suggesting differences were based on geochemical conditions. For reduced sediments deployed in B-02, populations of iron-reducing bacteria decreased in general as did total biomass, but were at least comparable to the sediment core samples. When reduced sediments were deployed in previously stimulated wells, populations of iron-reducing bacteria in ISI-deployed sediments, in general, only decreased slightly and seemed to represent a time-dependent shift toward the microbial community composition of the adjacent, native sediment of the test plots. This raises an important point - the ISI-deployed sediments were amended with an electron donor once and incubated in situ for seven months, whereas the test plots were subject to repeated cycles of acetate injections. Thus, differences in the microbial community composition between ISI-deployed reduced sediments, and the P-61 and P-62 sediment cores should be expected. In terms of validating the ISI approach at the Old Rifle site, however, the overall results demonstrate the ISIs can be used as in situ recorders of changes in sediment microbial community composition. Furthermore, the ISIs will be particularly beneficial when integrated into future field experiments.

\section{ACKNOWLEDGMENTS}

This research was supported by grants from the Office of Biological and Environmental Research (OBER) of the Office of Science, U.S. Department of Energy (DOE), Environmental Remediation Science Program (ERSP) project DE-FG02-04ER63939. The Pacific Northwest National Laboratory is operated for the U.S. Department of Energy under contract DE-AC05-76RL01830 with the Battelle Memorial Institute.

\section{REFERENCES}

Anderson, R. T., Rooney-Varga, J. N., Gaw, C. V., \& Lovley, D. R. (1998). Anaerobic benzene oxidation in the $\mathrm{Fe}(\mathrm{III})$ reduction zone of petroleum-contaminated aquifers. Environmental Science \& Technology, 32, 1222-1229.

Anderson, R. T., Vrionis, H. A., Ortiz-Bernad, I., Resch, C. T., Long, P. E., Dayvault, R., et al. (2003). Stimulating the in situ activity of Geobacter species to remove uranium from the groundwater of a uranium-contaminated aquifer. Applied and Environmental Microbiology, 69, 5884-5891.

Bekins, B. A., Godsy, E. M., \& Warren, E. (1999). Distribution of microbial physiologic types in an aquifer contaminated by crude oil. Microbial Ecology, 37, 263-275. 
Bennett, P. C., Hiebert, F. K., \& Rogers, J. R. (2000). Microbial control of mineral groundwater equilibria: Macroscale to microscale. Hydrogeology Journal, 8, 47-62.

Chang, Y.-J., Stephen, J. R., Richter, A. P., Venosa, A. D., Bruggemann, J., Macnaughton, S. J., et al. (2000). Phylogenetic analysis of aerobic freshwater and marine enrichment cultures efficient in hydrocarbon degradation: Effect of profiling method. Journal of Microbiological Methods, 40, 19-26.

Gorby, Y. A., \& Lovley, D. R. (1992). Enzymatic uranium precipitation. Environmental Science \& Technology, $26,205-207$.

Guckert, J. B., Antworth, C. P., Nichols, P. D., \& White, D. C. (1985). Phospholipid, ester-linked fatty acid profiles as reproducible assays for changes in prokaryotic community structure of estuarine sediments. FEMS Microbiology Ecology, 31, 147-158.

Hazen, T. C., Jimenez, L., de Victoria, G. L., \& Fliermans, C. B. (1991). Comparison of bacteria from deep subsurface sediment and adjacent groundwater. Microbial Ecology, 22, 293-304.

Hendricks, B., Dejonghe, W., Boenne, W., Brennerova, M., Cernik, M., Lederer, T., et al. (2005). Dynamics of an oligotrophic bacterial aquifer community during contact with a groundwater plume contaminated with benzene, toluene, ethylbenzene, and xylenes: An in situ mesocosm study. Applied and Environmental Microbiology, 71, 3815-3825.

Holmes, D. E., Finneran, K. T., O’Neil, R. A., \& Lovley, D. R. (2002). Enrichment of members of the family Geobacteraceae associated with stimulation of dissimilatory metal reduction in uranium-contaminated aquifer sediments. Applied and Environmental Microbiology, 68, 2300-2306.

Istok, J. D., Senko, J. M., Krumholz, L. R., Watson, D., Bogle, M. A., Peacock, A., et al. (2004). In situ bioremediation of technetium and uranium in a nitrate-contaminated aquifer. Environmental Science \& Technology, 38, 468-475.

Long, P. E., Williams, K. H., Yabusaki, S. B., Fang, Y., N'Guessan, L. A., Wellman, D. M., et al. (2008). Bioremediation of metals and radionuclides: Results from field-scale experiments and future prospects. American Geophysical Union Abstract H41L-04, San Francisco, California, December 15-19, 2008.

Lovley, D. R., \& Phillips, E. J. (1992). Reduction of uranium by Desulfovibrio desulfuricans. Applied and Environmental Microbiology, 58, 850-856.

Lovley, D. R., Phillips, E.J.P., Gorby, Y. A., \& Landa, E. R. (1991). Microbial reduction of uranium. Nature, 350, 413-416.

Mayberry, W. R., \& Lane, J. R. (1993). Sequential alkaline saponification/acid hydrolysis/esterification: A one-tube method with enhanced recovery of both cyclopropane and hydroxylated fatty acids. Journal of Microbiological Methods, 18, 21-26.

Mouser, P. J., N'Guessan, L. A., Elifantz, H., Holmes, D. E., Williams, K. H., Wilkins, M. J., et al. (in press). Influence of heterogeneous ammonium availability on bacterial community structure and the expression of nitrogen fixation and ammonium transporter genes during in situ bioremediation of uranium-contaminated groundwater. Environmental Science and Technology.

N'Guessan, A. L., Vrionis, H. A., Resch, C. T., Long, P. E., \& Lovley, D. R. (2008). Sustained removal of uranium from contaminated groundwater following stimulation of dissimilatory metal reduction. Environmental Science and Technology, 42, 2999-3004. 
Ortiz-Bernad, I., Anderson, R. T., Vrionis, H. A., \& Lovley, D. R. (2004). Resistance of solid-phase U(VI) to microbial reduction during in situ bioremediation of uranium-contaminated groundwater. Applied and Environmental Microbiology, 70, 7558-7560.

Peacock, A. D., Chang, Y.-J., Istok, J. D., Krumholz, L., Geyer, R., Kinsall, B., et al. (2004). Utilization of microbial biofilms as monitors of bioremediation. Microbial Ecology, 47, 284-292.

Petrie, L., North, N. N., Dollhopf, S. L., Balkwill, D. L., \& Kostka, J. E. (2003). Enumeration and characterization of iron(III)-reducing microbial communities from acidic subsurface sediments contaminated with uranium(VI). Applied and Environmental Microbiology, 69, 7467-7479.

Phelps, T. J., \& Fredrickson, J. K. (2002). Drilling, coring, and sampling subsurface environments. In M. J. Mclnerney (Ed.), Manual of environmental microbiology (2nd ed., pp. 679-696). Washington, DC: ASM Press.

Phelps, T. J., Raione, E. G., White, D. C., \& Fliermans, C. B. (1989). Microbial activity in deep surface environments. Geomicrobiology Journal, 8, 79-91.

Reardon, C. L., Cummings, D. E., Petzke, L. M., Kinsall, B. L., Watson, D. B., Peyton, B. M., et al. (2004). Composition and diversity of microbial communities recovered from surrogate minerals incubated in an acidic uranium-contaminated aquifer. Applied and Environmental Microbiology, 70, 6037-6046.

Roling, W.F.M., van Breukelen, B. M., Braster, M., Lin, B., \& van Verseveld, H. W. (2001). Relationships between microbial community structure and hydrochemistry in a landfill leachate-polluted aquifer. Applied and Environmental Microbiology, 67, 4619-4629.

Snoeyenbos-West, O. L., Nevin, K. P., Anderson, R. T., \& Lovley, D. R. (2000). Enrichment of geobacter species in response to stimulation of Fe(III) reduction in sandy aquifer sediments. Microbial Ecology, 39, 153-167.

Stults, J. R., Snoeyenbos-West, O., Methe, B., Lovley, D. R., \& Chandler, D. P. (2001). Application of the 5' fluorogenic exonuclease assay (TaqMan) for quantitative ribosomal DNA and rRNA analysis in sediments. Applied and Environmental Microbiology, 67, 2781-2789.

Suzuki, M. T., Taylor, L. T., \& DeLong, E. F. (2000). Quantitative analysis of small-subunit rRNA genes in mixed microbial populations via 5'-nuclease assays. Applied and Environmental Microbiology, 66, 4605-4614.

Thomas, R.A.P., Lawlor, K., Bailey, M., \& Macaskie, L. E. (1998). Biodegradation of metal-EDTA complexes by an enriched microbial population. Applied and Environmental Microbiology, 64, 1319-1322.

Vrionis, H. A., Anderson, R. T., Ortiz-Bernad, I., O’Neill, K. R., Resch, C. T., Peacock, A. D., et al. (2005). Microbiological and geochemical heterogeneity in an in situ uranium bioremediation field site. Applied and Environmental Microbiology, 71, 6308-6318.

Wall, J. D., \& Krumholz, L. R. (2006). Uranium reduction. Annual Reviews of Microbiology, 60, 149-166.

White, D. C., Bobbie, R. J., Heron, J. S., King, J. D., \& Morrison, S. J. (1979). Biochemical measurements of microbial mass and activity from environmental samples. In J. W. Costerton \& R. R. Colwell (Eds.), Native aquatic bacteria: Enumeration, activity and ecology (pp. 69-81). Philadelphia, PA: American Society for Testing and Materials.

Wilkins, M. J., Williams, K. H., Verberkmoes, N. C., Hettich, R. L., Lipton, M. S., Callister, S. J., et al. (2008). Proteogenomic analysis of geobacter populations in a low nutrient contaminated aquifer under stimulated conditions. American Geophysical Union Abstract B33C-0445, San Francisco, California, December 15-19, 2008. 